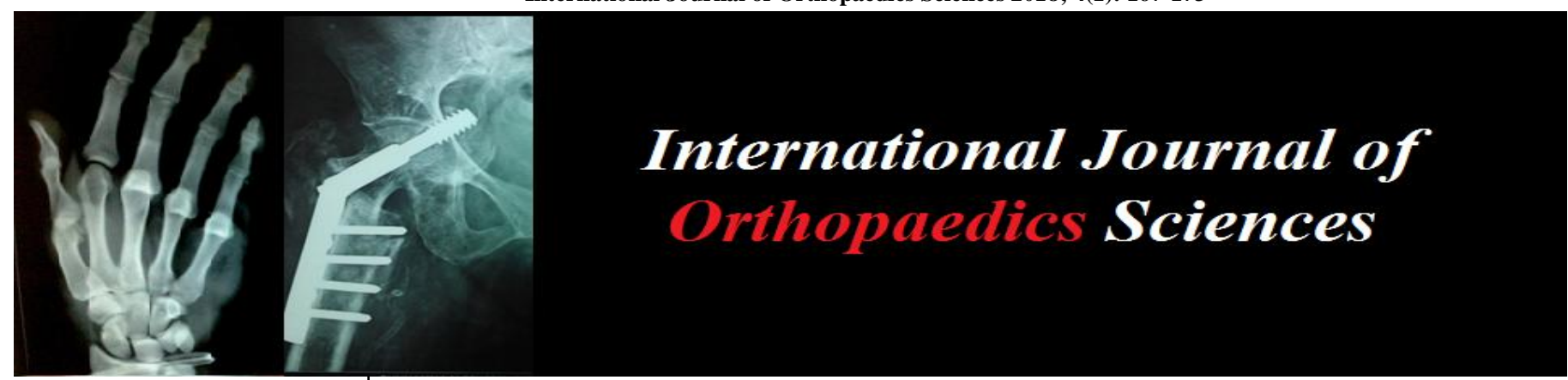

ISSN: $2395-1958$

IJOS 2018; 4(1): 167-173

(C) 2018 IJOS

www.orthopaper.com

Received: 26-11-2017

Accepted: 27-12-2017

Dr. Varun Chouhan

(M.S. Orthopedics)

Bombay Hospitals Indore,

Indore, India
Correspondence

Dr. Varun Chouhan

(M.S. Orthopedics)

Bombay Hospitals Indore,

Indore, India

\section{To assess the 2-year clinical and radiologic results with an entirely HA-coated total hip replacement, with an emphasis on periprosthetic bone remodelling}

\section{Dr. Varun Chouhan}

DOI: https://doi.org/10.22271/ortho.2018.v4.i1c.26

\begin{abstract}
Total hip arthroplasty (THA) is one of the most successful surgical procedures that has been introduced and today over 1.5 million THA's are performed annually in the world. The development of THA in the 60 's by Sir John Charnley represents a milestone in orthopaedic surgery. The most common indication for THA is primary osteoarthritis, a degenerative disorder of the cartilage and the surrounding tissues. However, $8-9 \%$ of the THA's performed sooner or later need to be re-operated. Revision arthroplasty is a challenging procedure, costly and with a less reliable outcome. The main reason for failure leading to revision is aseptic loosening. Both mechanical and biological effects act in the loosening process, the dominating factor may be one or the other, depending on a number of circumstances, including implant design, fixation mode and technique, as well as biologic factors unique to the individual. Our purpose of this study is to determine the performance of, and periprosthetic bone response to hydroxyapatite (HA)coated hip implant at least 2 years after insertion. This is both prospective \& retrospective study of patients operated with uncemented fully HA coated THR in our institute, Sample size taken is 30 patients of institute who have undergone uncemented fully HA coated THR. We have taken Patients with un cemented fully HA coated THR done, At least 2 year back in hospital as a Inclusion criteria. In exclusion criteria we have excluded Patient with uncemented partially HA coated THR and Patients with anterior thigh pain before operation. Our procedure of study was Clinical follow up of patients pre-op, immediate post op, 12months \& 24 months using anterior thigh pain. Radiological follow up through x-rays at preop, immediate post op, 12 months \& 24 months. Anteroposterior radiographs of the pelvis and femurs cantered over the pubis, and lateral views of the femurs were standardized by using the same film quality, developing process, exposure, target distance, magnification, and field and keeping the leg in the same position. The linear measurements were made by a calliper and corrected for magnification of the radiographs, using the diameter of the head of the femoral component as reference. Femoral zonal analysis was performed on the anteroposterior radiographs as described by Gruen $e$ al. and on the lateral radiographs according to Johnston et al. spot welds that is diaphyseal endosteal bone formation were noted in both anteroposterior and lateral x-rays. Subsidence of the stem was measured by the vertical distance from the lateral shoulder of the prosthesis to the superior tip of the greater trochanter or to the tip of the lesser trochanter. Varus or valgus migration was determined by measuring the angle made by the intersection of a line through the midstem of the prosthesis and a line through the midshaft of the femur as seen on the anteroposterior radiograph. End point of study was completion of clinical and radiological follow up of 30 patients.

Results shown by this study reviews 38 hips in 30 patients who were followed up for a average of 32 months (range 24- 96 months). There were 22 male and 8 female patients. The average age was 41 years (range, 14-55 years). The diagnosis was AVN in 28 hips, Ankylosing spondylitis in 7 hips, Fracture neck femur in 2 hips, Koch's in 1 hip. 6 hips had undergone prior procedures, including osteosynthesis of femoral neck fracture. Clinically Result shows Hip function rose to a near-normal level during the first year, and this result was maintained throughout the study. At 2 years, only 1 patient complained of vague, uncharacteristic hip pain, unrelated to walking. No patient suffered from thigh pain.
\end{abstract}

Keywords: Total hip arthroplasty (THR), cementless arthroplasty, Periprosthetic bone density, hydroxyapatite (HA)-coated hip implant, HA-coated total hip replacement

\section{Introduction}

Total hip arthroplasty is a very successful reproducible procedure and an excellent treatment to eliminate pain and restore function in a diseased hip for both the short-term and long-term period. An extensive body of literature documents both functional improvement and high rates of long term survivorship for this procedure. 
As a result both indications and expectations for total hip arthroplasty have continued to broaden as new advances are incorporated.

The ability of hydroxyapatite (HA) to bond directly to bone quickly and strongly has been used by plasma spraying of HA coatings on hip prostheses. Preliminary reports on HA-coated hip prostheses are limited but mostly encouraging. The clinical effect of coating limitation is uncertain, and because the major problem with cementless prostheses has been loosening, extensive coating that may increase fixation seems more rational.

Periprosthetic bone density change is a common finding in total hip arthroplasty (THA). It has been suggested that when bone loss is excessive, it can compromise the long-term clinical performance of the prosthesis. Periprosthetic bone loss was first observed around failed cemented femoral stems; it was related to aseptic loosening, and it was named "cement disease".

\section{Methods}

This is both prospective \& retrospective study of patients operated with uncemented fully HA coated THR in our institute.

\section{Definitions used as reference}

$>$ Bone ingrowth: It is the term used to describe biological response when new bone tissue is found in direct contect with the surface of non-cemented implant. Synonym bone ongrowth, osseointegration, biological ingrowth.

$>$ Bone remodelling: It refers to mechanically adaptive changes in bony architecture.

$>$ Spot weld: endosteal new bone formation bridging from cortical bone and in apposition of implant surface, seen as densification on radiographs.

$>$ Pedestal formation: Radiological endosteal densification at the tip of stems, partially or completely bridging the medullary canal. synonym tip sclerosis

$>$ Reactive lines: radiological endosteal densification parallel to the lining of the implant, normally with in millimeter distance from implant surface. synonym: radiodence line, radioopaque line, sclerotic line, cortical line.

$>$ Subsidence of the stem: Measured by the vertical distance from the lateral shoulder of the prosthesis to the superior tip of the greater trochanter or to the tip of the lesser trochanter.

$>$ Varus or valgus migration: Determined by measuring the angle made by the intersection of a line through the midstem of the prosthesis and a line through the midshaft of the femur as seen on the anteroposterior radiograph.

$>$ Stress shielding: Osteopenia occurring in bone as the result of removal of normal stress from the bone by an implant.

Sample size taken is 30 patients of institute who have undergone uncemented fully HA coated THR. We have taken Patients with uncemented fully HA coated THR done, At least 2 year back in hospital as an Inclusion criteria. In exclusion criteria we have excluded Patient with uncemented partially HA coated THR and Patients with anterior thigh pain before operation.

Our procedure of study was Clinical follow up of patients preop, immediate post op, 12 months \& 24 months using anterior thigh pain. Radiological follow up through x-rays at pre-op, immediate post op, 12 months \& 24 months. Anteroposterior radiographs of the pelvis and femurs cantered over the pubis, and lateral views of the femurs were standardized by using the same film quality, developing process, exposure, target distance, magnification, and field and keeping the leg in the same position. The linear measurements were made by a calliper and corrected for magnification of the radiographs, using the diameter of the head of the femoral component as reference. Femoral zonal analysis was performed on the anteroposterior radiographs as described by Gruen et al. and on the lateral radiographs according to Johnston et al. spot welds that is diaphyseal endosteal bone formation were noted in both anteroposterior and lateral x-rays. Subsidence of the stem was measured by the vertical distance from the lateral shoulder of the prosthesis to the superior tip of the greater trochanter or to the tip of the lesser trochanter. Varus or valgus migration was determined by measuring the angle made by the intersection of a line through the midstem of the prosthesis and a line through the midshaft of the femur as seen on the anteroposterior radiograph. End point of study was completion of clinical and radiological follow up of 30 patients.

\section{Results}

This study reviews 38 hips in 30 patients who were followed up for a average of 32 months (range 24- 96 months). There were 22 male and 8 female patients. The average age was 41years (range, 14-55 years). The diagnosis was AVN in 28 hips, Ankylosing spondylitis in 7 hips, Fracture neck femur in 2 hips, Koch's in 1 hip. 6 hips had undergone prior procedures, including osteosynthesis of femoral neck fracture. Clinically Result shows Hip function rose to a near-normal level during the first year, and this result was maintained throughout the study. At 2 years, only 1 patient complained of vague, uncharacteristic hip pain, unrelated to walking. No patient suffered from thigh pain.

\section{Femoral Radiographic Results}

$>$ Stem subsidence or loosening was not seen in any case.

$>5$ stems had been inserted into the varus whereas 4 in valgus position.

\begin{tabular}{|c|c|c|}
\hline Alignment & Hips & Percentage (\%) \\
\hline Central & 29 & $76 \%$ \\
\hline Varus & 5 & $13 \%$ \\
\hline Valgus & 4 & $11 \%$ \\
\hline Total & 38 & $100 \%$ \\
\hline
\end{tabular}

$>10$ stems had not been completely buried in the femoral bone, so that $6 \mathrm{mrn}$ of the HA coated part protruded above the calcar resection level. Within the first 2 years, new bone grew up as far as $4 \mathrm{~mm}$ along 6 of these prostheses (Fig. 1).

Figure (1) showing new bone formation in calcar region.

$>$ Decrease in calcar height was not seen in any case. Rounding of the calcar started at 6 months in 12 hips, at 1 year in 8 hips, and at 2 years in 2 hips, whereas the remaining 10 calcars showed no rounding.

$>$ We regularly found cancellous bone remodeling in the proximal femur, resulting in trabecular reorientation. In addition, diaphyseal endosteal bone formation with socalled spot welds was found in all cases (Fig. 2). This formation was first seen at 6 months in 19 hips, at 1 year in 12 hips, and at 2 years in 5 hips. 


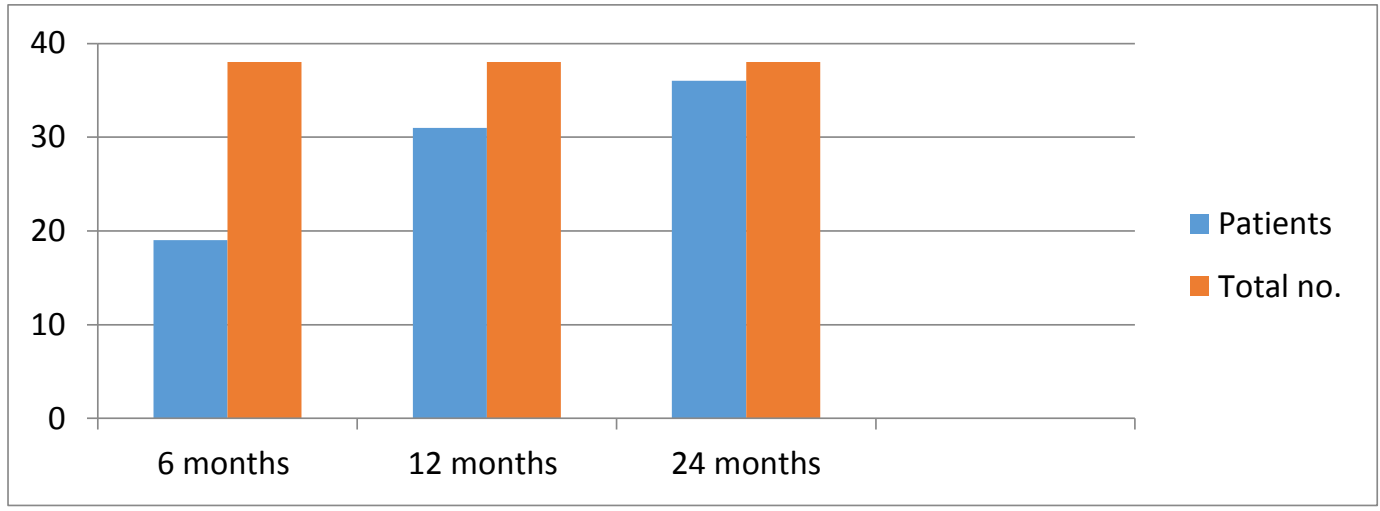

Fig 2: showing multiple spot-weld formation at 2 years.

Table 2. Showing spot-weld formation in femoral stem with time

\begin{tabular}{|c|c|c|}
\hline & Patients & Percentage (\%) \\
\hline 6 months & 19 & $50 \%$ \\
\hline 12 months & 12 & $32 \%$ \\
\hline 24 months & 5 & $13 \%$ \\
\hline Total & 36 & $95 \%$ \\
\hline
\end{tabular}

The endosteal bone density increased until 2 years.

$>$ Considerable trabecular bone formation was noted at the tip of the stem found in 6 hips (Fig. 2). The cancellous bone always connected the tip to the nearest cortex (Fig.3) or to both in case of the tip being centered in the femoral canal. Four femurs with valgus stems developed cortical thickening in zones 4 and 5. This thickening was first seen at 1 year, slightly increasing throughout the study. The tips of these stems were lying against the endosteal cortex, causing a bony reaction with cortical thickening (Fig. 3). In 2 cases calcar was fractured, both of them being secured with wire loops, healed uneventfully.

Figure (3) showing pedestal (black arrow) and spot-weld formation.

$>$ Stem subsidence or loosening was not found in any of these cases.

$>$ In the anteroposterior view, 32 hips showed stress shielding which was present throughout the follow up (Fig 4). In the lateral view, 32 femurs showed decrease in bone density. No correlation was found between decreased bone density and stem size, canal fill, sex, age, or body weight.

Figure (4) showing stress shielding both in calcar and greater trochantric region

Table 3: Showing $\%$ of stress shielding noted on x-rays:

\begin{tabular}{|c|c|c|}
\hline Stress shielding & Patients & Percentage (\%) \\
\hline Present & 32 & $84 \%$ \\
\hline Absent & 6 & $16 \%$ \\
\hline
\end{tabular}

Radiopaque double lines were seen along the proximal part of 5 femoral stems, always locatedboth in zone 1 (Fig. 5). The lines were present till 2 years of follow up. The mean length of the lines in zone 1 was $4 \mathrm{~mm}$. The width was aorund $1 \mathrm{~mm}$. We found no association between the development of proximal radiopaque double lines and sex, age, body weight, stem size, canal fill, or polyethylene wear.

Figure (5) showing radiopaque line formation.

\section{Discussion}

This is a study of a prospectively and retrospectively collected series of hip arthroplasty using a tapered, titanium, Hydroxyappatite coated hip stem. The concept of osseointegration is related to a high degree of direct boneimplant contact without intervening soft tissue, as ascertained by microscopic evaluation. Intimate radiologic bone-implant contact is essential however does not guarantee of bone fixation; a thin layer of fibrous tissue can be concealed in the interface. The surrounding of a prosthesis by a radiopaque double line correlates histologically with a fibrous tissue layer between implant and bone. In such cases, the development of clinically significant failure is inevitable. Migration of an implant that is bonded to bone is hardly possible. Cementless prostheses surrounded by an extensive radiopaque double line (so-called fibrous fixation) or revealing measurable migration or subsidence should be considered loosenings because they have not achieved the intentional direct bone-implant contact. Loosening should be separated into primary nonintegration and loosening of implants previously bonded directly to bone. The femoral implant evaluated in this study has been shown to perform quite well historically and in this group of patients, it developed osseointegration with clear evidence in all cases of endosteal spot welds and trabecular bridging. There were no cases of aseptic loosening, with a stable bone response demonstrated reliably at greater than 2 years of follow-up. There was no evidence of subsidence or component migration, indicating that implant stability was achieved early and reliably. The results of this study are comparable to those reported by Rokkum and Reigstad. In their review of 94 consecutive cases, with careful radiographic and clinical follow up, there was no observed stem subsidence or loosening in any case. They regularly found cancellous bone remodeling in the proximal femur, with preservation of the osseous architecture. The Proximal osteolysis was minimal and distal osteolysis absent, despite a high rate of acetabular failure in their study.

In a retrieval analysis of this implant, Tonino et al found that all 5 stems were well fixed in the femur, and there was a significant evidence of both distal and proximal osseointegration. Although the relative contribution of the hydroxyapatite coating to the success of this implant cannot be determined by this study, there is considerable clinical and experimental evidence suggesting that such coatings enhance initial fixation and ultimate osseous integration. Comparative studies have indicated advantages of HA-coated implants over noncoated implants of similar design, with HA-coated femoral stems achieving more reliable bony fixation, better evidence of spot welds, and less subsidence than porous control groups. 
The tapered geometry of this implant may also have played a significant role in the osseous integration and bone adaptation that was observed in this study. Long-term success has been documented with other tapered stems, without hydroxyapatite coating. Comparison of early postoperative with long-term radio-graphs, however, does demonstrate preservation of bone architecture, with similar appearance of bone quality, both early and late. In addition, the complete absence of thigh pain noted in this group of patients may be related to this favourable bone response without significant hypertrophy or remodeling. It has been documented that despite the high rate of acetabular wear, there were no cases of significant femoral osteolysis. There was no distal osteolysis; when present, lysis was confined by a sclerotic zone to the proximal zones of the implant and was not progressive. It is likely that the circumferential and complete coating of the implant conferred upon it a resistance to progressive and distal manifestations of osteolysis.

The most striking clinical finding in our study was the absence of thigh pain, which is often seen both in proximally and in fully porous-coated stems as well as in proximally
HAcoated stems, even with histologically verified bone ingrowth. Mismatch between the modulus of elasticity of the bone and prosthesis and diaphyseal endosteal irritation by an unstable stem have been proposed as causes of thigh pain. Thigh pain seems to be eliminated with the entirely HAcoated stem, probably because of comprehensive diaphyseal bonding.

This study documents the success of this tapered, titanium, HA-coated femoral stem in a consecutive series of unselected cases with no failure of fixation or aseptic loosening though stress shielding was present in majority of cases. The implant was found to perform with equal success across a wide range of pathologic entities, patient profiles, and bone types. Although the relative contributions of the surface coating, the implant geometry, and the surgical technique of compaction broaching cannot be established by this study, it is clear that this combination of features resulted in a durable and reliable femoral construct for this group of patients. Further documentation of the performance of this device into the second decade of service and beyond will be necessary to determine if these favorable results are maintained.
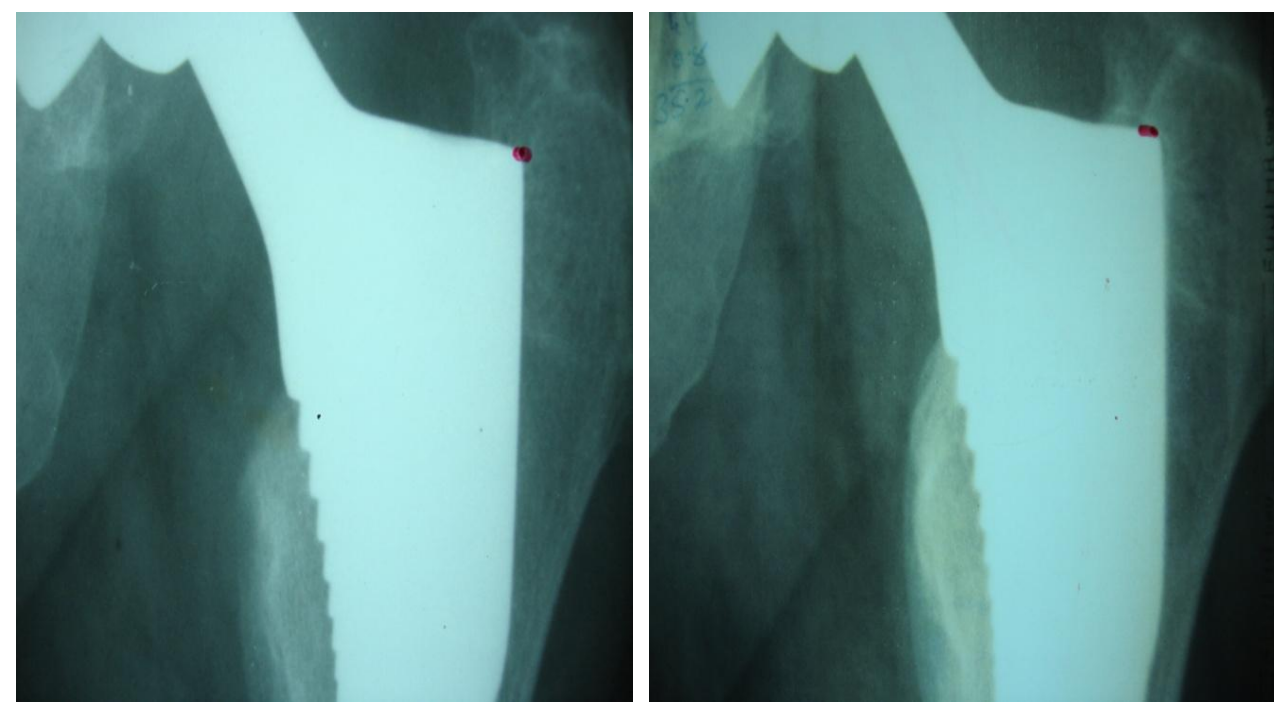

Fig 1: showing new bone formation in calcar region.

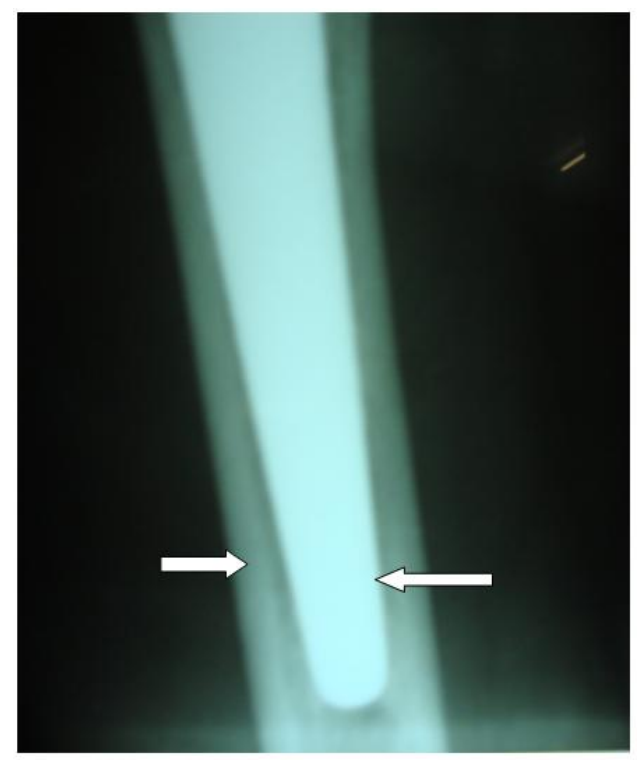

Fig 2: Showing multiple spot-weld formation at 2 years. 
Table 2: Showing spot-weld fomation in femoral stem with time

\begin{tabular}{|c|c|c|}
\hline & Patients & Percentage (\%) \\
\hline 6 months & 19 & $50 \%$ \\
\hline 12 months & 12 & $32 \%$ \\
\hline 24 months & 5 & $13 \%$ \\
\hline Total & $\mathbf{3 6}$ & $\mathbf{9 5 \%}$ \\
\hline
\end{tabular}
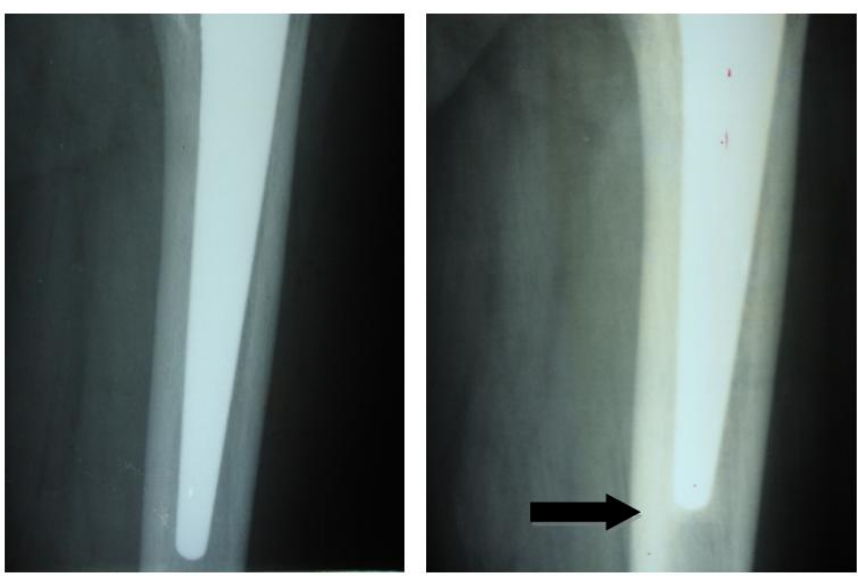

Fig 3: Showing pedestal (black arrow) and spot-weld formation.
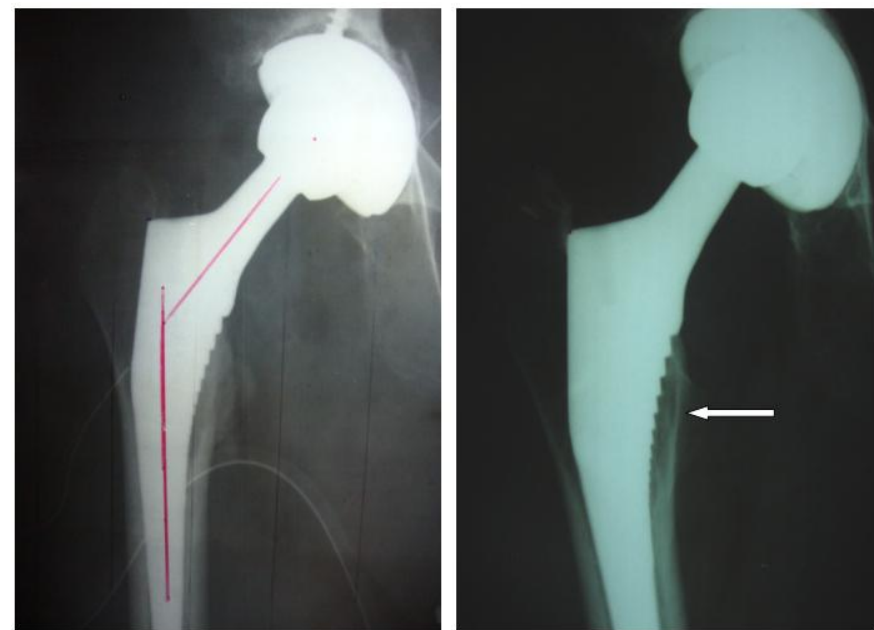

Fig 4: Showing stress shielding both in calcar and greater trochantric region

Table 3: Showing \% of stress shielding noted on x-rays

\begin{tabular}{|c|c|c|}
\hline Stress Shielding & Patients & Percentage (\%) \\
\hline PRESENT & 32 & $84 \%$ \\
\hline ABSENT & 6 & $16 \%$ \\
\hline
\end{tabular}

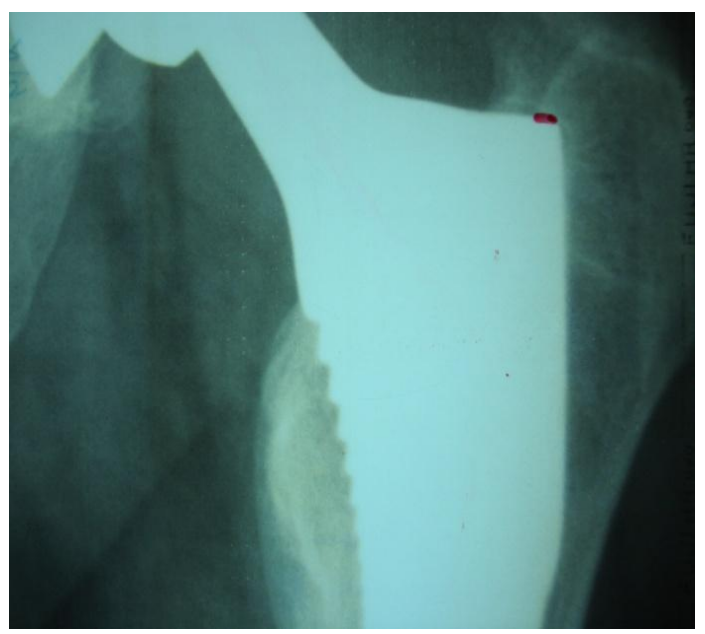

Fig 5: Showing radiopaque line formation

\section{Funding: Self}

\section{Conflict of interest: Nil}

Ethical approval: Taken from the Hospital Ethical committee

\section{References}

1. Froimson Mark I. MD, MBA, Garino Jonathan, MD, Machenaud Alan , MD, and Vidalain J.P., MD, Minimum 10-year Results of a Tapered, Titanium, HydroxyapatiteCoated Hip Stem, The Journal of Arthroplasty Vol. 22 No. 12007.

2. Callaghan JJ, Albright JC, Goetz DD et al. Charnleyn total hip arthroplasty with cement. Minimum twentyfive-year follow-up. J Bone Joint Surg Am 2000; 82:4 87.

3. Ebramzadeh E, Normand PL, Sangiorgio SN et al. Longterm radiographic changes in cemented total hip arthroplaty with six designs of femoral components. Biomaterials 2003; 24:3351.

4. Ebramzadeh E, Sarmiento A, McKellop HA et al. The cement mantle in total hip arthroplasty. Analysis of longterm radiographic results. J Bone Joint Surg Am 1994; 76:77.

5. Keener JD, Callaghan JJ, Goetz DD et al. Twentyfiveyear results after Charnley total hip arthroplasty in patients less than fifty years old: a concise followup of a previous report. J Bone Joint Surg Am. 2003; 85:1066.

6. McLaughlin JR, Lee KR. Total hip arthroplasty with an uncemented femoral component. Excellent results at tenyear follow-up. J Bone Joint Surg Br. 1997; 79:900.

7. Schulte KR, Callaghan JJ, Kelley SS et al. The outcome of Charnley total hip arthroplasty with cement after a minimum twenty-year follow-up. The results of one surgeon. J Bone Joint Surg Am. 1993; 75:961.

8. Wroblewski BM, Siney PD. Charnley low-friction arthroplasty of the hip. Long-term results. Clin Orthop. 1993; 292:191.

9. Rokkum M, Reigstad A. Total hip replacement with an entirely hydroxyapatite-coated prosthesis: 5 years' follow-up of 94 consecutive hips. J Arthroplasty 1999; 14:689.

10. Lemons JE: Hydroxyapatite coatings. Clin Orthop 1988, 235:220.

11. D'Antonio JA, Capello WN, Jaffe WL. Hydroxylapatitecoated hip implants: multicenter threeyear clinical and roentgenographic results. Clin Orthop. 1992, 285:102.

12. Geesink RG, Hoefnagels NH. Six-year results of hydroxyapatite-coated total hip replacement. J Bone Joint Surg Br. 1995, 77:534,

13. Tonino AJ, Romanini L, Rossi $\mathrm{P}$ et al. Hydroxyapatitecoated hip prostheses: Early results from an international study. Clin Orthop, 1995, 312:211.

14. Donnelli WJ, Kobayashi A, Freeman MAR et al. Radiologica and survival comparison of four methods of fixation of a proximal femoral stem. J Bone Joint Surg Br. 1997, 79:3.

15. Karachalios Theofilos MD, Tsatsaronis Christos MD, Efraimis George MD, Papadelis Panagiotis MD, Lyritis George MD, Diakoumopoulos George MD. The LongTerm Clinical Relevance of Calcar Atrophy Caused by Stress Shielding in Total Hip Arthroplasty.

16. Gluck T. Autoplastic-transplantation-implantation,Von 
fremkorpern, Klin 1890; 27;421.

17. Pean JE. Des moyens prosthetiqus destines aobtenir la reparation des parties osseses, Gaz de Hop Paris, 1894.

18. Lawrence V, Gulotta MD. Andreas Baldini, MD \& Kristin Foote, MEd \& Stephen Lyman, PhD \& Bryan J. Nestor, MD. Femoral Revision with an Extensively Hydroxyapatite-Coated Femoral Component.

19. Paolo Rossi MD, Piero Sibelli MD. Sergio Fumero, MD; and Emanuela Crua, MD; Short-Term Results of Hydroxyapatite-Coated Primary Total Hip Arthroplasty, Clin Orthop. 1995; 310; 98-102.

20. Bloebaump Roy D MD, Errell Markm MD, Kennethg Ustke MD, Immons Michaels MD. Retrieval Analysis of a Hydroxyapatite-Coated Hip Prosthesis.

21. Rorabeck CH MD, FRCS Ghazal ME MD, Lee MH MD. Pain in the Thigh following Total Hip Replacement with a Porous-Coated Anatomic Prosthesis for Osteoarthrosis; J Bone Joint Surg Am. 1994; 76:1464-1470.

22. Campbell ACL Rorabeck CH, Bourne RB, Chess D, Nott L. Thigh pain after cementless hip arthroplasty.

23. Rudolph GT, Geesink MD. PhD Osteoconductive Coatings for Total Joint Arthroplasty. Clin Orthop, 2002; 395:53-65.

24. Kromann-Andersetn, Scherff Spirensen, Hougaard K, Zdravkovi D, Frigaard CE. Ectopic bone formation following charnley hip arthroplasty. Actaorthop. scand. 1980; 51:633-638.

25. Bauerm Thomasw D, Taylorm Scottk S, Jiang M, Medendorpm Sharonv. An Indirect Comparison of ThirdBody Wear in Retrieved Hydroxyapatite-Coated, Porous, and Cemented Femoral Components. Clin Orthop. 1994; 298:11-18.

26. Willem M van Leeuwen, Patrick Deckers, Willem J de Lange. Preoperative irradiation for prophylaxis of ectopic ossification after hip arthroplasty. Acta Orthop Scand. 1998; 69(2):116-118.

27. Camazzola Dan MD, Hammond Terry MD, Gandhi Rajiv MD, Davey J. Roderick MD. A Randomized Trial of HA coated Femoral Stems in Total Hip Arthroplasty: A 13Year Follow-Up; The Journal of Arthroplasty. 2009, 24:1

28. Rajiv Gandhi MD, J Roderick Davey MD. HA coated femoral stems in Primary Total Hip Arthroplasty: A Meta-Analysis. The Journal of Arthroplasty, 2009, 24, 1.

29. Havelin LI, Espehaug B, Vollset SE et al. Early aseptic loosening of uncemented femoral components in primary total hip replacement. A review based on the Norwegian Arthroplasty Register. J Bone Joint Surg Br. 1995; 77:11.

30. Reikeras O, Gunderson RB. Excellent results of HA coating on a grit-blasted stem, 245 patients followed for 8-12 years. Acta Orthop Scand. 2003; 74:140.

31. Tonino AJ, Therin M, Doyle C. Hydroxyapatite coated stems. Histology and histomorphometry around five components retrieved at postmortem. J Bone Joint Surg Br. 1999; 81:148.

32. Sbballe K, Hansen ES, Rasmussen HB et al. Tissue ingrowth into titanium and hydroxyapatite-coated implants during stable and unstable mechanical conditions. J Orthop Res. 1992; 10:285.

33. Dalton JE, Cook SD, Thomas KA et al. The effect of operative fit and hydroxyapatite coating on the mechanical and biological response to porous implants. J Bone Joint Surg Am 1995; 77:97.

34. Stephenson PK, Freeman MAR, Revell PA et al. The effect of hydroxyapatite coating on ingrowth of bone into cavities in an implant. J Arthroplasty, 1991; 6:51.
35. Kroon PO, Freeman MA. Hydroxyapatite coating of hip prostheses. Effect on migration into the femur. J Bone Joint Surg Br. 1992; 74:518.

36. McPherson EJ, Dorr LD, Gruen TA et al. Hydroxyapatite-coated proximal ingrowth femoral stems. A matched pair control study. Clin Orthop 1995; 315:223.

37. Tanzer M, Kantor S, Rosenthall L et al. Femoral remodeling after porous-coated total hip arthroplasty with and without hydroxyapatite-tricalcium phosphate coating: a prospective randomized trial. J Arthroplasty. 2001; 16:552.

38. Capello WN, D'Anotnio JA, Manley MT et al. Hydroxyapatite in total hip arthroplasty. Clinical results and critical issues. Clin Orthop. 1998; 355:200.

39. Purtill JJ, Rothman RH, Hozack WJ et al. Total hip arthroplasty using two different cementless tapered stems. Clin Orthop 2001; 393:121.

40. Lai KA, Shen WJ, Chen $\mathrm{CH}$ et al. Failure of hydroxyapatite-coated acetabular cups. Ten-year followup of 85 Landos Atoll arthroplasties. J Bone Joint Surg Br 2002; 84:641.

41. Albrektsson T, Albrektsson B. Osseointegration of bone implants: a review of an alternative mode of fixation. Acta Orthop Scand. 1987; 58:567.

42. 50. Engh CA, Bobyn JD, Glassman AH: Porous-coated hip replacement: the factors governing bone ingrowth, stress shielding, and clinical results. J Bone Joint Surg Br. 1987; 69:45.

43. Pidhorz LE, Urban RM, Jacobs JJ et al. A quantitative study of bone and soft tissues in cementless porouscoated acetabular components retrieved at autopsy. J Arthroplasty. 1993; 8:213.

44. Geesink RG, de Groot K, Klein CP. Chemical implant fixation using hydroxyl-apatite coatings: the development of a human total hip prosthesis for chemical fixation to bone using hydroxyl-apatite coatings on titanium substrates. Clin Orthop. 1987; 225:147.

45. Gottlander M. On hard tissue reactions to hydroxyapatitecoated titanium implants. Thesis. Biomaterials Group, Dept of Handicap Research, Institute for Surgical Sciences, University of Goteborg, Goteborg, Sweden, 1994.

46. Soballe K. Hydroxyapatite ceramic coating for bone implant fixation: mechanical and histological studies in dogs. Acta Orthop Scand 255(suppl): 26, 1993.

47. Cook SD, Thomas KA, Kay JF, Jarcho M. Hydroxyaparite- coated titanium for orthopedic implant applications. Clin Orthop. 1988; 232:225.

48. Cooke FW. Ceramics in orthopedic surgery. Clin Orthop. 1992; 276:i35.

49. Ducheyne P, Cuckler JM. Bioactive ceramic prosthetic coatings. Clin Orthop. 1992; 276:102.

50. Lemons JE. Hydroxyapatite coatings. Clin Orthop. 1988; 235: 220.

51. Haddad RJ, Cook SD, Brinker MR. A comparison of three varieties of noncemented porous-coated hip replacement. J Bone Joint Surg Br. 1990; 72:2.

52. Heekin RD, Callaghan JJ, Hopkinson WJ et al. The porous-coated anatomic total hip prosthesis, inserted without cement: results after five to seven years in a prospective study. J Bone Joint Surg Am, 1993; 75:77.

53. Kim YH, Kim VE. Uncemented porous-coated anatomic total hip replacement: results at six years in a consecutive series. J Bone Joint Surg Br. 1993; 75:6. 
54. Lachiewicz PE, Anspach WE 3d, DeMasi R. A prospective study of 100 consecutive Harris-Galante porous total hip arthroplasties: 2-5-year results. J Arthroplasty. 1992; 7:519.

55. Learmonth ID, Grobler GP, Dall DM, Jandera V: Loss of bone stock with cementless hip arthroplasty. J Arthroplasty. 1995; 10:257.

56. Maric Z, Karpman RR. Early failure of noncemented porous coated anatomic total hip arthroplasty. Clin Orthop. 1992; 278:116.

57. Martell JM, Pierson RH 3d, Jacobs JJ et al. Primary total hip reconstruction with a titanium fiber-coated prosthesis inserted without cement. J Bone Joint Surg Am. 1993; 75:554.

58. Buma P, Gardeniers JW. Tissue reactions around a hydroxyapatite-coated hip prosthesis: case report of a retrieved specimen. J Arthroplasty. 1995; 10:389. 